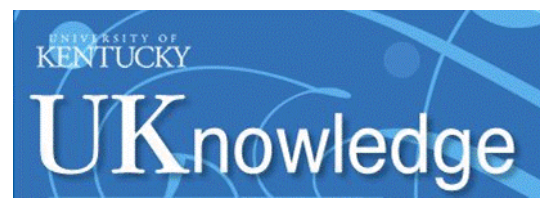

University of Kentucky

UKnowledge

$11-22-2016$

\title{
Students' Views on General Education: Insights Gained from the Narratives of Chinese Students in Hong Kong
}

\author{
Daniel T. L. Shek \\ University of Kentucky \\ Florence K. Y. Wu \\ The Hong Kong Polytechnic University, China \\ Wen Yu Chai \\ The Hong Kong Polytechnic University, China
}

Follow this and additional works at: https://uknowledge.uky.edu/pediatrics_facpub

Part of the Chinese Studies Commons, Curriculum and Instruction Commons, and the Higher Education Commons

Right click to open a feedback form in a new tab to let us know how this document benefits you.

\section{Repository Citation}

Shek, Daniel T. L.; Wu, Florence K. Y.; and Chai, Wen Yu, "Students' Views on General Education: Insights Gained from the Narratives of Chinese Students in Hong Kong" (2016). Pediatrics Faculty Publications. 285.

https://uknowledge.uky.edu/pediatrics_facpub/285

This Article is brought to you for free and open access by the Pediatrics at UKnowledge. It has been accepted for inclusion in Pediatrics Faculty Publications by an authorized administrator of UKnowledge. For more information, please contact UKnowledge@lsv.uky.edu. 


\section{Students' Views on General Education: Insights Gained from the Narratives of Chinese Students in Hong Kong}

Digital Object Identifier (DOI)

https://doi.org/10.1515/ijdhd-2017-7013

\section{Notes/Citation Information}

Published in International Journal on Disability and Human Development, v. 16, issue 4, p. 443-450.

(C2017 Walter de Gruyter GmbH, Berlin/Boston.

The copyright holder has granted the permission for posting the article here. 


\section{Daniel T.L. Shek*, Florence K.Y. Wu and Wen Yu Chai}

\section{Students' views on general education: insights gained from the narratives of Chinese students in Hong Kong}

DOI 10.1515/ijdhd-2017-7013

Received August 20, 2016; accepted September 25, 2016; previously published online November 22, 2016

\begin{abstract}
The General University Requirements (GUR) is a component of the new 4-year undergraduate program at The Hong Kong Polytechnic University (PolyU). This study examined students' views and experiences of the GUR using a qualitative methodology. Written comments of 240 freshmen, sophomores, and senior-year students with reference to open-ended questions on their memorable experiences in the GUR study were collected. The qualitative findings suggested that students generally had positive views on the GUR in terms of its widely adopted active and experiential learning pedagogy, useful and attractive contents, caring teaching staff, and rich learning outcomes. Challenges were also identified for further improvement of the GUR.
\end{abstract}

Keywords: experiential learning; general education; higher education; Hong Kong; qualitative research.

\section{Introduction}

Historically, general education has been an essential part of American college education. It is a common education for all undergraduates aiming to offer students broad exposure to different knowledge disciplines and nurture their intellectual and civic attributes [1]. For many centuries, the value of general education was constantly claimed and

*Corresponding author: Daniel T.L. Shek, Associate Vice President (Undergraduate Programme) and Chair Professor of the Department of Applied Social Sciences, The Hong Kong Polytechnic University, Hunghom, Hong Kong, P.R. China; Centre for Innovative Programmes for Adolescents and Families, The Hong Kong Polytechnic University, Hong Kong, P.R. China; Department of Social Work, East China Normal University, Shanghai, P.R. China; Kiang Wu Nursing College of Macau, Macau, P.R. China; Hong Kong Institute of Service Leadership and Management, Hong Kong, P.R. China; and Division of Adolescent Medicine, Kentucky Children's Hospital, University of Kentucky, Lexington, KY, USA, E-mail: daniel.shek@polyu.edu.hk Florence K.Y. Wu and Wen Yu Chai: Department of Applied Social Sciences, The Hong Kong Polytechnic University, Hong Kong, P.R. China was regarded as more significant in contemporary society. Along with the development of science and technology, as well as increased specialization of knowledge since the 20th century, general education becomes more important as it is a good counter-measure to the overspecialization of knowledge through providing students with a common body of knowledge and intellectual experiences [2, 3]. In other words, general education is vital to prevent disconnections and disunity in students' learning [4]. As argued by Boyer and Levine [5], "overspecialization, excessive vocationalism, and above all, the free-elective system were criticized for ignoring the broad purposes of education. General education, it was argued, would help restore the balance" (p. 30). Also, McGrath [6], a former editor of The Journal of General Education, claimed that general education was "the unifying element of a culture. It embraces the great moral truths, the scientific generalizations, the aesthetic conceptions, and the spiritual values of the race, ignorance of which makes men incapable of understanding themselves and the world in which they live” (p. 3).

In modern societies, general education also assumes the task of helping students develop to be effective and functional citizens to tackle complicated problems that are hard to be solved by knowledge from one discipline [7]. With the emergence of globalized knowledge economies, there are increasing insecurity and instability in career development for university graduates. Hence, nurturing university students to be flexible and have transferrable generic skills to be successful in society is an important task for university educators [2, 8]. Against this background, more and more governments acknowledged the importance of general education in their manpower development and incorporated general education programs into the curricula of their higher education [9]. In the USA, the value of general education has also been reclaimed as an important strategy for empowering university students to compete in a global and multicultural society [10].

General education has also been rigorously introduced in the undergraduate curriculum of the Hong Kong higher education system. Before the handover back to China in 1997, Hong Kong had developed a higher education tradition that inherited the structure of British higher education. Its undergraduate degree program was featured by 
a 3-year curriculum with early specialization in students [11]. In this structure, general education only occupied a marginalized place. However, Hong Kong carried out a reform on its higher education system after the handover to transform its 3-year British style of higher education into a 4-year American style of higher education. Commencing from the fall of 2012, mandated by the University Grants Committee (UGC), a government advisory committee for higher education funding and development, all the eight public universities in Hong Kong changed their undergraduate degree programs. Specifically, the length of all 3-year undergraduate degree programs was changed to 4 years. At the same time, a foundational general education component was introduced into the new 4-year undergraduate curriculum in each university.

With specific reference to The Hong Kong Polytechnic University (PolyU), along with the transition from a 3-year to a 4-year structure of undergraduate education, PolyU developed a significant general education component named General University Requirements (GUR) in its new 4-year curriculum. With its six featured components, the GUR aimed to nurture the graduates with five desired graduate attributes, including effective communication, critical thinking, innovative problem solving, lifelong learning, and ethical leadership. The six components of the GUR are as follows:

- Freshman Seminar (FS, three credits): FS is a mandatory subject for first-year students. It is offered by each faculty/school to their students regardless of their specializations. It introduces students to their potential disciplines and majors.

- Leadership and Intrapersonal Development (LIPD, three credits): LIPD aims to develop students' interpersonal and intrapersonal qualities conducive to effective and ethical leadership. While students at the Faculty of Business take "Tango! Managing Self and Others" (Tango!), other students take a subject entitled "Tomorrow's Leaders" (TL).

- Language and Communication Requirements (LCR, nine credits). LCR aims to strengthen students' language proficiency in both English and Chinese. In this component, all students are required to take two English subjects (six credits) and one Chinese subject (three credits).

- Cluster Area Requirements (CAR, 12 credits). CAR aims to expose students to the knowledge of different knowledge disciplines. It also tries to develop students' understanding of China and their reading and writing skills. In this component, students are required to take one elective subject from each of the four cluster areas of learning. The four cluster areas are CAR-A "Human Nature, Relations and Development”, CAR-B "Community, Organization and Globalization", CAR-C "History, Culture and World Views", and CAR-D "Science, Technology and Environment". Besides, students also need to fulfill three additional requirements in the CAR subjects: (a) China studies requirements (CSR), (b) English writing and reading requirements (EW/ER), and (c) Chinese writing and reading requirements $(\mathrm{CW} / \mathrm{CR})$.

- Service Learning (SL, three credits). SL aims to help students apply academic knowledge in solving realworld problems, help them reflect on their roles as responsible citizens, and develop their empathy and civic responsibility.

- Healthy Lifestyle (HLS, non-credit-bearing). HLS helps students to establish a healthy lifestyle. Students are required to complete a program with four components covering different dimensions of health: introductory lecture, sports training, e-learning, and wrap-up lecture.

A unique feature of the GUR is its active and experiential learning pedagogy embedded in different program components. For example, group project work is widely adopted as a major approach of student learning and assessment in subjects of different GUR components including FS, LIPD, CAR, and SL. Meanwhile, experiential learning occupies a significant component in subjects in SL and HLS components. In addition, the writing assignment is also adopted as a major means of assessment in many subjects.

Although the value of general education and its benefits to student development have been proposed by different philosophers and educators for centuries, empirical studies on how students perceive general education and its effects on their development are not adequate. Some limited number of studies give insights into this area. For example, Twombly [12] found that while some students perceived general education as helpful to their academic confidence, study habits, social network, and major selection, more students perceived a failed alignment of general education with its intended goals. Twombly [12, 13] found that students valued general education programs that were more related to their professional goals. King and Kotrlik [14] suggested that students preferred general education curricula that were broad and gave them more flexibility. Schee [15] found that the general education first-year seminar introducing students to their broad disciplines and university academic life enhanced their appreciation of the general education program and their confidence in subject selection in general education. Some newly promoted curriculum mode in general 
education such as SL was found to have a high positive impact on student development in terms of critical thinking, writing skills, leadership, problem solving, interpersonal skills, and self-efficacy $[16,17]$. These studies suggested what curricula factors were perceived by students as effective in promoting their positive learning in general education. Nevertheless, the available studies were based on the contexts of American higher education, which does not reflect students' views on general education in higher education in other cultural contexts.

Against this background, the present study investigated how students perceived the GUR in the new 4-year curriculum of PolyU through collecting and analyzing the written responses of the students to open-ended questions. The present study was one component of a 5-year longitudinal evaluation project starting from the 2012-2013 academic year to evaluate the implementation and effectiveness of the GUR at PolyU. The project comprised several major components, including objective outcome evaluation based on a 4-year longitudinal online survey, subjective outcome evaluation based on student feedback questionnaires, and qualitative evaluation based on student and teacher focus groups, and students' and teachers' written responses to qualitative evaluation forms. The objective outcome evaluation findings revealed that students had a significantly positive change on important inter- and intrapersonal attributes [18, 19]. The subjective outcome evaluation findings showed that GUR subjects were generally well received by students and promoted students' learning experiences over time [20]. Because these evaluation studies were based on quantitative methods, they could not show the subjective experiences of the students. Although focus group is a good method to collect students' views, it is more resource-consuming compared with written responses because much time and manpower are required for focus group interviews and transcription tasks. Also, individual student views could be influenced by their peers in focus group interactions. Therefore, analysis of individual written responses to open-ended questions is an alternative way to collect students' views in an efficient and objective manner. In this study, a qualitative evaluation of the GUR based on students' written responses was carried out.

\section{Methods}

Participants were students enrolled in the 4-year undergraduate curriculum at PolyU in the 2012-2013, 2013-2014, and 2014-2015 academic years. In the end of December 2014, a total of 480 students enrolled in the new 4-year curriculum were randomly selected. Each of the 60 students was randomly selected from the student population of each of eight faculties/schools from three cohorts, i.e. the 2012-2013, 2013-2014, and 2014-2015 cohorts. These students were invited by phone and email to complete an online evaluation form. Up until mid-January 2015, a total of 332 students completed the form. Due to the large amount of data and the different types of questions in the form, the present study was only based on students' responses to open-ended questions: "Do you have any memorable experiences in your study of GUR subjects? If 'yes', would you share your experiences with us?" Among the 332 students who had completed the evaluation form, 240 students responded to the open-ended questions. The numbers of students who responded to the questions by faculty and by cohort are listed in Table 1 .

\section{Instrument}

The whole evaluation form was developed by the authors to collect students' views about different aspects of GUR implementation from both quantitative and qualitative approaches. Therefore, the form comprised both closed-ended and open-ended questions. The closed-ended questions focused on students' ratings of their understanding of the new 4-year curriculum and the GUR. The open-ended questions focused on descriptors given by students to describe their impressions of the GUR and the open-ended questions on their memorable experiences in their study of GUR subjects. The present study focused on students' responses to the following open-ended questions: "Do you have any memorable experiences in your study of GUR subjects? If 'yes', would you share your experiences with us?" This question was designed to understand the implementation and perceived effectiveness of the GUR from the perspective of the students.

\section{Data analyses}

All the responses were input into an Excel file. A postdoctoral fellow carefully read these responses three times, and coded all the responses into different themes. Responses under each theme were further coded into sub-themes. A more detailed description of each code is given below.

Table 1: Numbers of participants by faculty and cohort in GUR qualitative evaluation.

\begin{tabular}{lrrrrrrrrrr}
\hline Cohort & \multicolumn{1}{c}{} & & & & & & & \multicolumn{3}{c}{ Faculty } \\
\cline { 2 - 11 } & FAST & FB & FCE & FENG & FH & FHSS & SD & SHTM & Total \\
\hline $2012-2013$ & 9 & 7 & 5 & 11 & 10 & 9 & 4 & 9 & 64 \\
$2013-2014$ & 12 & 11 & 14 & 13 & 12 & 10 & 10 & 5 & 87 \\
$2014-2015$ & 15 & 8 & 9 & 10 & 12 & 12 & 9 & 14 & 89 \\
Total & 36 & 26 & 28 & 34 & 34 & 31 & 23 & 28 & 240 \\
\hline
\end{tabular}

FAST, Faculty of applied science and textiles; FB, faculty of business; FCE, faculty of construction and environment; FENG, faculty of engineering; FH, faculty of humanities; FHSS, faculty of health and social sciences; SD, school of design; SHTM, school of hotel and tourism management. 


\section{Results}

Five themes emerged from the coding. They were "Active and experiential learning", "Interesting and useful contents", "Positive and rich learning outcomes", "Caring, helpful and qualified Teachers", and "Challenges". The following part elaborates these themes one by one.

\section{Active and experiential learning}

The majority of the students expressed that they had gained most memorable experiences through joining different kinds of active and experiential learning activities in the GUR. Firstly, students perceived that most of the GUR subjects adopted group project works in their teaching and assessment sections. These group project experiences were "interesting" and helpful to students' competences in thinking and teamwork. This can be illustrated by the following responses.

- "Yes. Most of GUR subjects consist of group projects which I found interesting to work with others."

- "In CAR subject, we were given a whole tutorial session to present our findings and the classmates could discuss our findings and voice out different opinions. That was memorable."

- "Have a 'formal' project in FS and Tomorrow's Leaders which can experience the attitude and how to work together, so that I can have experience in doing project in the next few years."

Students also expressed that the experiential learning experiences, particularly those offered by SL subjects, confronted them with people in different cultures and situations. Particularly, by helping underprivileged people in local and foreign cultures, students had most striking memorizations in learning. They did more self-reflection on their current life, learned contribution and appreciation, and developed a sense of meaning and achievement. These perceptions of students are illustrated by the following responses.

- "In Service Learning, I met a good lecturer with [a] great course. I went to Sichuan and conducted service there. I learned so many things through the lectures and the service trip there. I had experienced something I won't forget, lifelong lasting and meaningful."

- "Service Learning is the most meaningful and valuable subject among all GUR subjects. I learn to appreciate and contribute. I think the school can put more emphasis on this subject."
- "Service Learning provides a great chance for me to live in village in Indonesia which was an unforgettable experience that I would never have in the future. It let me reflect on myself that I have owned a lot in Hong Kong and treasure what I have now. Thanks for the SL subject."

Students were also impressed by other experiential learning activities, such as fieldwork. For example, two students consistently expressed that their most memorable experience in the GUR study was coming from the fieldwork experience in one CAR subject named First Bucket of Gold in China. Through the fieldwork, the students experienced the local culture in China and "understand the enterprises in Hangzhou". Students also enjoyed very much about some CAR subjects that combined experiential learning and high-quality class teaching. This is illustrated by the following narratives.

- "The subject First Bucket of Gold in China was really impressive. There was a trip to Hangzhou. The trip provided a lot of chances for us to understand the enterprises in Hangzhou and was very interesting. The workload is suitable and the lecturer can explain the theories very clearly. It is also very practical for our future."

- "The Chinese Wisdom is the course I enjoyed the most with a lively teaching and field trips."

\section{Interesting and useful contents}

Students generally had positive perceptions of the content of the GUR subjects. They especially showed their fondness of subject content in the TL, HL, and CAR components. Students thought that the topics in TL were inspiring and reflective. The knowledge and skills learned from the subject could be applied to students' daily lives, as shared by the following responses.

- "Among these subjects, Tomorrow's Leaders is my favorite subject as it is really useful in my daily life. In daily life, I have faced some emotional problem[s] which I could not deal with. However, during the lesson, I got help from this lesson. It helped me to find out the best way to solve the problem. This experience is really memorable and meaningful to me."

- "Yes, lectures of Tomorrow's Leaders are inspiring and help me reflect what is lacking in my intrapersonal development."

Students also expressed their fondness for the HLS component, particularly for the sports skills training session. 
Actually, to make the component more attractive, the HLS component was designed to incorporate many novel and interesting sports skills in its sports skills training session, such as fencing, frisbee, and squash. Students gained great fun from playing these sports. They also established a close relationship with their peers in the classes, as expressed by the following responses.

- "Yes, the sports skills class (fencing) is a very good experience. It is an uncommon sport in secondary schools and I am really pleased that GUR offered such a course!"

- "Having squash classes at university made me feel like going back to the time in secondary school. I had great fun with other classmates and we laughed a lot during the sports skills training course.”

Some students also perceived that the topics in some CAR subjects were interesting and exposed them to new areas of knowledge, as shared by the following responses.

- "Attending The Evolution of World Cuisine is very great because I had chance to try many new things."

- "Cluster area requirements (CAR) course Court and Palace: Power and Intrigue in Imperial China gives me a valuable learning experience."

- "The course, Introduction to Sociology APSS112, is memorable, a whole new area of study."

\section{Positive and rich learning outcomes}

A set of positive learning outcomes from the GUR were identified from students' responses. These included a broadened knowledge base and horizon, writing and speaking skills, teamwork skills, interpersonal relationship, healthy lifestyle, social responsibility, and a changed attitude towards life. For example, some students responded that:

- "I think the study of GUR subjects is far different from the past. It is more diverse, so that I can broaden my horizons."

- "CAR-D course provides me a lot and it triggers me a new route in my life."

- "Tomorrow's Leaders helps build up inter- and intrapersonal relationship."

Interestingly, it could be identified that there was a relationship between active and experiential learning activities and students' development of learning outcomes in their GUR study. For example, through SL, particularly through experiencing different cultures and helping underprivileged people in service activities, a few students learned how to treasure their current life and developed a sense of responsibility to society. One student shared his response as follows:

- "In last semester, I joined a Service Learning course, [during] which [I] went to Qinghai and Guizhou to provide vision screening for local students. It was joyful and memorable experience for me because it was the first time I went to do voluntary work in China. I felt my work has greater purpose other than getting good grades and the joy from helping others is unforgettable."

Different group projects and writing assessments in different GUR subjects provided plenty of opportunities for students to practice their teamwork, writing skills, and oral expression skills, as shared by following responses.

- "I wrote from the beginning to the end, total 12 pages in the final exam of a CAR subject, it is amazing!"

- "Yes, I have written a long story in creative writing course and I gained a high satisfaction."

- In the study of Freshman Seminar, once we were hoped to describe 'creativity'. It was the first time I stood in front of many people to speak out my innermost thoughts and feelings. This impressed me and encouraged me."

- "It is nice to cooperate with others in Freshman Seminar and it is very memorable to work with my groupmates overnight in order to finish our work and to have final adjustment."

\section{Caring, helpful, and qualified teachers}

Students had a very positive impression of some of their GUR teachers. They were deeply impressed by these teachers' caring and helpful attitude and appreciated it very much. This was illustrated by the following narratives:

- "Alice (alias for confidentiality) who is one of the instructors of Tomorrow's Leaders is very nice and helpful"

- "Except [for] one CAR teacher, all the other CAR teachers that have taught me were very passionate and helpful. They knew our needs and were eager to provide learning materials."

- " "The most memorable experience in my GUR subject study is Tomorrow's Leaders, as the lecturer is nice and tries to invite us to share our story."

Some teachers' qualified teaching and caring attitudes also promoted students' deep and active learning of 
the subjects. This has been illustrated by the following responses:

- "I particularly enjoyed Tomorrow's Leaders subject, and my lecturer has been very motivating and sincere during lectures. I learned a lot about life and being a good leader and did a lot of meaningful reflections."

- "My English teacher John (alias for confidentiality) is a very patient and caring teacher. His way of teaching makes the learning atmosphere very relaxing and good. He makes students communicate well with one another."

- "Yes, my lecturer in Freshman Seminar appreciated our efforts of deliberating a good presentation. And I really appreciated her for treating me, my teammates and the free rider fairly."

\section{Challenges}

Two major challenges in studying GUR subjects emerged from the student responses. The first challenge was the students' difficulty in subject registration of the CAR subjects. Several students perceived that it was difficult for them to register the CAR subjects that they were interested in. Besides, difficulty in fulfilling the reading and writing requirements and the CSR of CAR was noted. Heavy timetable clashes between many CAR subjects and students' other prescribed subjects were also shown by the findings. Some students also encountered difficulties in registering the HLS subjects. They worried whether they could fulfill the requirements of HLS on time as shared by the following responses:

- 'I couldn't register Healthy Lifestyle [courses] in every semester. All the vacancies were taken by people. Please open more vacancies. And I always get time crash with the pre-assigned subjects and the CAR and Service Learning subjects. It is hard to prepare a good timetable."

- "Hard to register the CAR subject I want and fulfill the requirement. Always vacancy zero.”

Another challenge mentioned by some of the students was the reluctant or negative attitudes towards studying GUR subjects, particularly when the CAR subjects were far beyond their own majors. Particularly, a few students majoring in social sciences or humanities expressed their unwillingness to study science subjects in the CAR-D area. They had less interest in studying science subjects because they could not perceive the relationship between these subjects and their majors and they had a weak background in science. This can be illustrated by a response below:

- $\quad$ "In fact I am an APSS student and I find it useless for us to study CAR-D [subjects]. We should not be asked to learn CAR-D right? It's a trap for those who are interested in social science as a number of us are bad at science."

\section{Discussion}

The present study investigated how students perceived the GUR in the new 4-year undergraduate curriculum at PolyU. Several major observations are gained from the findings. Primarily, students perceived that active and experiential teaching and learning methods widely adopted in GUR subjects (such as group project work and SL) were very useful. These methods facilitated student learning in the GUR. They also promoted students' development in a variety of inter- and intrapersonal competences such as thinking, teamwork, civic value, and self-reflection. This finding was in line with other qualitative findings on the GUR in the same and in different years [21-23].

The findings have two implications. First, the findings indicated that the GUR at PolyU was generally effective in promoting students' inter- and intrapersonal development. Second, the findings suggested that active and experiential teaching and learning methods were a key factor to the effectiveness of general education courses. The findings are in line with the general scientific literature. For example, research suggests that SL had positive impacts on a variety of aspects of student development, including social competence, social responsibility, the ability to work with students with diversified backgrounds, cognitive complexity, self-assurance, and personal efficacy [24-26]. Results from the present study further strengthened these findings by showing that SL experiences changed students' attitudes towards life, promoted their self-reflections on life and society, and helped them break through their own narrowness to be concerned more about society and others.

Secondly, students had positive perceptions about the subject contents of the GUR. Particularly, they perceived the contents of some GUR subjects, such as TL, to be very useful and applicable to their daily lives. The subject helped students reflect on their intra- and interpersonal development and helped them tackle their developmental problems. Research found that the emotional and anxiety problems of first-year undergraduate students in Hong Kong were relatively high [27]. Based on the positive youth 
development approach, the rationale behind TL was to promote students' leadership and intrapersonal competences. Existing studies suggested that TL was positively evaluated by students in terms of its learning experiences and achievement of intended learning outcomes [28, 29]. Previous studies also showed that TL was effective in promoting students' inter and intrapersonal development, self-reflection, and self-understanding [30, 31]. Findings from the present study further strengthened these existing findings by showing how students benefited from TL based on qualitative research findings.

Thirdly, the teacher was another important factor for the effectiveness of the GUR. Findings of the present study suggested that the caring attitude and behavior of some teachers greatly facilitated students' learning and personal development. This observation is consistent with the literature suggesting that teachers' caring behavior was influential to students' development. For example, research indicated that caring teachers could strengthen teacher-student relationships, increase students' confidence in teachers, and increase students' motivation to succeed [32]. Studies also found that teachers showing more enthusiasm for teaching would deliver higher quality of teaching [33] and foster more meaningful learning in students [34]. Enthusiastic teachers provide stimulus that attracts the attention of students, and promote their adaptation as well as experience of their enthusiastic attitudes and emotions, which would facilitate their deep engagement in learning [33].

Finally, two major challenges were identified in the implementation of the GUR. One challenge was students' registration of the CAR and HLS subjects. This might be due to several possible reasons. Firstly, students' subject registration in CAR was restricted by the "multiple" requirements. For example, although there were many CAR subjects on offer in each academic year, only about one-third of these subjects had English reading and writing requirements, and less than one-third of these subjects had Chinese reading and writing requirements. In order to fulfill the multiple requirements of CAR, students had to select from the subjects with English and Chinese reading and writing requirements. This limited the scope of their selection. Secondly, the students' tight study schedule in one semester was also a reason for their difficulty in registering the CAR subjects. Although there were many CAR subjects on offer, students had to choose those that fit into their busy schedule. Meanwhile, these subjects should also fulfill reading and writing requirements. This increased students' difficulty in registering the CAR subjects. The other challenge was a few students' negative attitudes towards studying science subjects in CAR because they majored in humanities and social sciences. One reason might be that some science subjects in CAR were designed with more advanced content which was far beyond social science students' knowledge background. Although it is a challenge to deliver a science subject to non-science major students, careful revision on science subjects and related faculty training should be conducted to promote students' learning in this area. Despite these challenges, findings of the present study suggest that the implementation of the GUR is smooth and effective from the students' perspective.

Acknowledgments: The authors thank The Hong Kong Polytechnic University for providing financial support via the Teaching Development Grant in conducting the 5-year GUR evaluation study.

\section{References}

1. Wehlburg CM. Integrated general education: a brief look back. New Dir Teach Learn 2010;2010:3-11.

2. Harvard University. General education in a free society; report of the Harvard Committee. Cambridge, MA: Harvard University Press, 1945.

3. Hutchins RM. The higher learning in America. New Haven, CT: Yale University, 1936.

4. Stevens $A H$. The philosophy of general education and its contradictions: the influence of Hutchins. J Gen Educ 2001;50:165-91.

5. Boyer EL, Levine A. A quest for common learning. Change: the Magazine of Higher Learning 1981. URL:http://www.tandfonline. com/doi/pdf/10.1080/00091383.1981.10569804.

6. McGrath E. The general education movement: an editorial. J Gen Educ 1946;1:3-8.

7. Newton RR. Tensions and models in general education planning. J Gen Educ 2000;49:165-81.

8. Brubacher JS. On the philosophy of higher education. San Francisco, CA: Jossey-Bass, 1982.

9. Jun X, Ng P, Cheng C. General education and the development of global citizenship in Hong Kong, Taiwan and mainland China: not merely icing on the cake. London: Routledge, 2013.

10. Association of American Colleges and Universities. College learning for the new global century. URL: https://www.aacu.org/ sites/default/files/files/LEAP/GlobalCentury_final.pdf.

11. Jaffee D. The general education initiative in Hong Kong: organized contradictions and emerging tensions. High Educ 2012;64:193-206.

12. Twombly SB. General education: the insiders' view. New Dir Higher Educ 1992;1992:91-103.

13. Twombly SB. Student perspectives on general education in a research university: an exploratory study. J Gen Educ 1992;41:238-72.

14. King LO, Kotrlik JW. Relevance of the general education core curriculum to career goals of college of agriculture students. J Agr Educ 1995;36:26-33. 
15. Vander Schee BA. Changing general education perceptions through "perspectives" and the interdisciplinary first-year seminar. Int J Teach Learn High Educ 2011;23:382-7.

16. Astin AW, Vogelgesang LJ, Ikeda EK, Yee JA. How service learning affects students. URL: http://digitalcommons.unomaha.edu/ cgi/viewcontent.cgi?article $=1145 \&$ context=slcehighered.

17. Moely BE, McFarland M, Miron D, Mercer S, Ilustre V. Changes in college students' attitudes and intentions for civic involvement as a function of service-learning experiences. Mich J Commun Serv Learn 2002;9:18-26.

18. Shek DT, Yu L. General university requirements and holistic development in university students in Hong Kong. Int J Adolesc Med Health 2016; Epub ahead of print 14 Jun 2016. DOI:10.1515/ ijamh-2017-3006.

19. Shek DT, Yu L. The impact of 3-year and 4-year undergraduate programs on university students: the case of Hong Kong. Int J Adolesc Med Health 2016; Epub ahead of print 14 Jun 2016. DOI:10.1515/ijamh-2017-3007.

20. Shek DT, Yu L, Ngai J. Evaluation of a general education program in Hong Kong: secondary data analyses based on student feedback questionnaires. Int J Disabil Hum Dev 2015;14:401-6.

21. Shek DT, Yu L, Chai WY. Evaluation of the general university requirements: What did students say? Int J Adolesc Med Health 2016; Epub ahead of print 14 Jun 2016. DOI:10.1515/ijamh-20173010.

22. Shek DT, Yu L, Wu FK, Chai WY. General University Requirements at The Hong Kong Polytechnic University: evaluation findings based on student focus groups. Assess Eval High Educ 2014;40:1017-31.

23. Shek DT, Lu Y, Zhu X. Qualitative evaluation of a new general education program in Hong Kong: findings based on students. Int J Disabil Hum Dev, in press.

24. Eyler J, Giles DE, Stenson CM, Gray CJ. At a glance: What we know about the effects of service-learning on college students, faculty, institutions and communities, 1993-2000: Third edition. University of Nebraska Omaha. URL: http://digitalcommons.unomaha.edu/cgi/viewcontent.cgi?article $=1137 \&$ context =slcehighered.

25. Kendrick JR. Outcomes of service-learning in an introduction to sociology course. Mich J Commun Serv Learn 1996;3:72-81.

26. Osborne RE, Hammerich S, Hensley C. Student effects of servicelearning: tracking change across a semester. Mich J Commun Serv Learn 1998;5:5-13.

27. Shek DT, Sun RC, Chui YH, Lit SW, Yuen WW, Chung YY, et al. Development and evaluation of a positive youth development course for university students in Hong Kong. ScientificWorldJournal 2012;8:DOI:10.1100/2012/263731.

28. Shek DT, Yu L. Student feedback on a subject on leadership and intrapersonal development for university students in Hong Kong. Int J Disabil Hum Dev 2016;15:339-46.

29. Shek DT, Yu L, Xie QZ. Student feedback on a pioneer subject on leadership and intrapersonal development in Hong Kong. Int J Adolesc Med Health 2016; Epub ahead of print 14 Jun 2016. DOI:10.1515/ijamh-2017-3011.

30. Shek DT, Sun RC. Focus group evaluation of a positive youth development course in a university in Hong Kong. Int J Disabil Hum Dev 2012;11:249-54.

31. Shek DT, Sun RC. Promoting psychological competencies in university students: evaluation based on a one-group pre-test/ post-test design. Int J Disabil Hum Dev 2012;11:229-34.

32. Owens LM, Ennis CD. The ethic of care in teaching: an overview of supportive literature. Quest 2005;57:392-425.

33. Kunter M, Tsai Y, Klusmann U, Brunner M, Krauss S, Baumert J. Students' and mathematics teachers' perceptions of teacher enthusiasm and instruction. Learn Inster 2008;18:468-82.

34. Keller M, Neumann K, Fischer HE. Teacher enthusiasm and student learning. In: Hattie J, Anderman EM, editors. International guide to student achievement. New York: Routledge, 2013. 